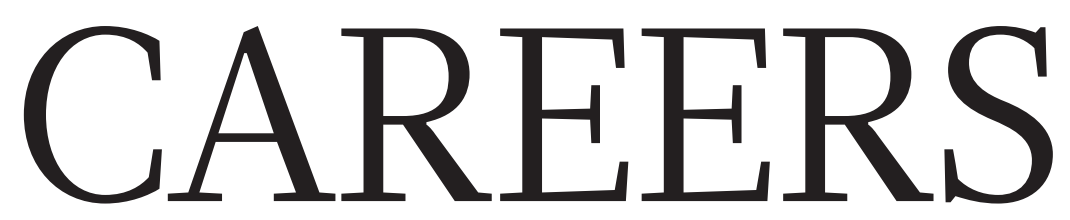

TURNING POINT Geneticist finds recognition as an innovator and toolmaker $\mathbf{p . 3 7 1}$
NATUREJOBS FACEBOOK Science-job resources, discussions and more go.nature.com/4/zxra
NATUREJOBS For the latest career

listings and advice www.naturejobs.com

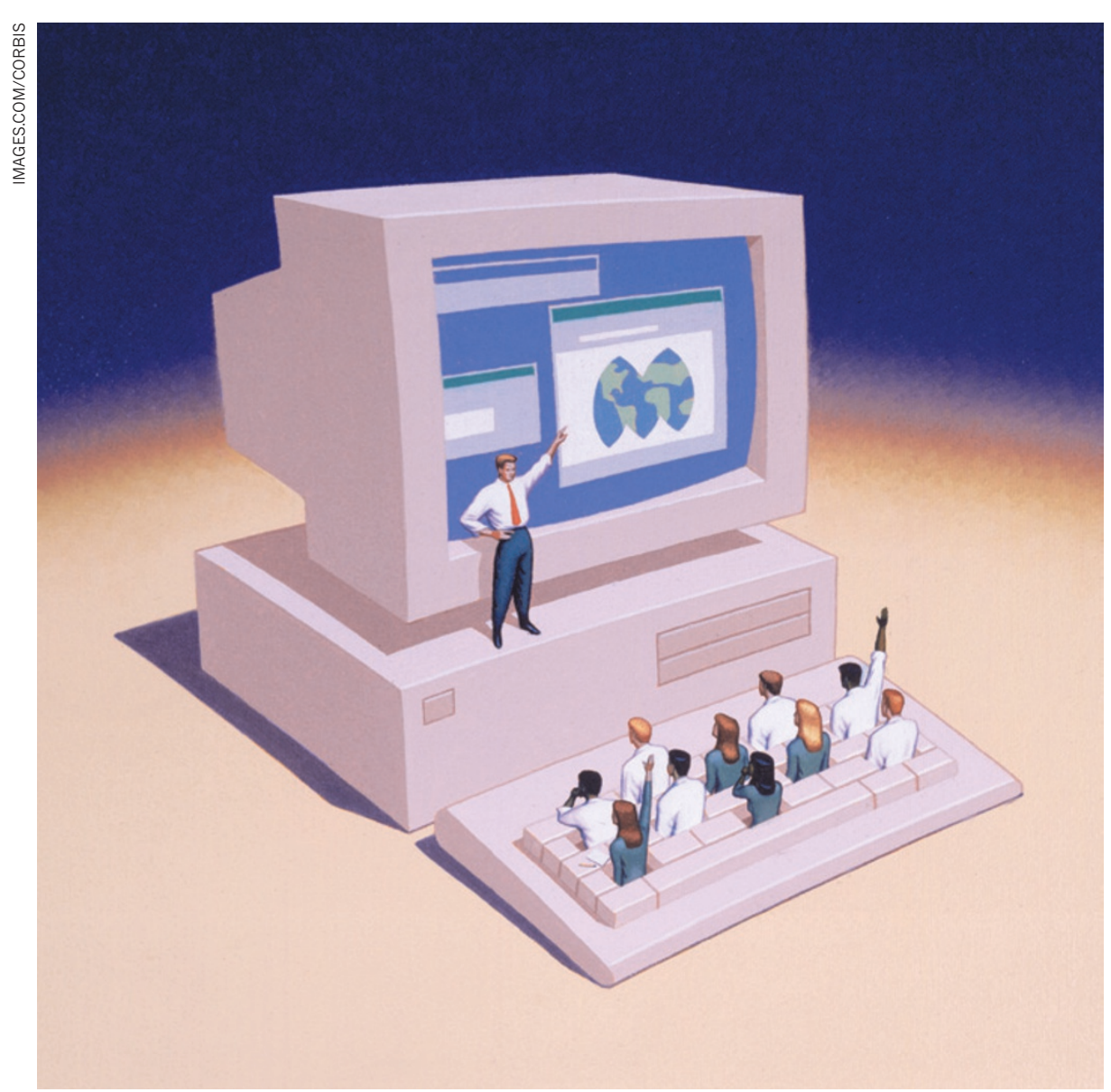

ONLINE LEARNING

\title{
a MOOC
}

\section{With forethought and support, science instructors can design effective massive open online courses.}

\section{BY SARAH KELLOGG}

W hen Marnie Blewitt was designing her first online epigenetics course, she knew that she would need help. A geneticist at the University of Melbourne in Australia, Blewitt was new to the business of MOOCs - massive open online courses that can reach thousands or even hundreds of thousands of students around the globe.

Blewitt enlisted Kylie Greig, a biology postdoc with an aptitude for technology, to help her to construct quizzes, create instructional slides and images and manage online student forums during the six-week course, which launched on 1 July on Coursera in Mountain View, California
— the largest MOOC platform worldwide. Blewitt and Greig will also work together to analyse test data and determine whether they need to add new content to clarify certain principles.

The help was crucial. "It is a very different feeling from a regular university course," says Blewitt. "The sheer number of students just really adds to the pressure, and also the knowledge that people will post immediately if they don't like it."

In the past couple of years, academic institutions, policy centres and research institutes around the world have become partners with MOOC providers including Coursera, edX in Cambridge, Massachusetts, and Udacity in Mountain View (see Comment, page 275). Coursera has so far registered 9.5 million enrolments; edX counts some 1 million. Institutions or instructors looking to go it alone can post lecture videos on YouTube.

MOOCs, which are usually free of charge, have course assignments and exams like their on-campus cousins, but they also feature discussion boards on which tens of thousands of students can gather to share ideas and discuss lectures. Course subjects are as disparate as the students, ranging from 'Artificial Intelligence for Robotics' to the 'History of Rock: Part Two' (which covers music, not minerals).

Instructors may feel daunted by the challenge of making a popular course shorter, livelier and easily understood on a computer screen. However, experienced MOOC designers say that the task is well worth the effort, because the courses allow for experimentation on a grand scale. Although it does not generally bring in extra pay, MOOC work gives teachers a chance to develop fresh methods for teaching science, bringing it to new, uninitiated audiences and encouraging cutting-edge discussions.

\section{A DIFFERENT WORLD}

MOOC creation requires rigorous attention to detail, with long hours of preparation and instruction. Successful courses are more than a lecture uploaded to the Web, say experts, and they serve a broader and more varied audience than other types of distance learning.

"Instructors designing MOOCs have to think through the whole new medium," says Anant Agarwal, president of edX and a computer scientist at the Massachusetts Institute

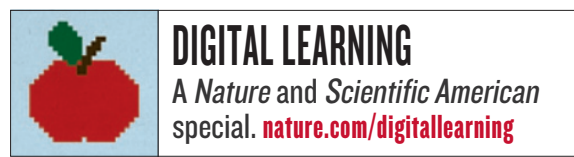


of Technology (MIT) in Cambridge. "How can materials be given to students in bite-sized chunks? You cannot stand at a board and talk for an hour, because students will lose interest, and you have to use discussion boards to guide student conversations about the material."

MOOCs also differ from on-campus teaching in that students do not necessarily learn the same thing at the same time. Udacity makes its courses available all year round, so that students can work at their own pace, and MOOCs on YouTube or other online-learning sites may be available in perpetuity, although instructors or universities often take down outdated material. By contrast, edX and Coursera offer courses at specific scheduled times, to ensure that student discussion boards and forums are monitored, and that all students are at the same point in their studies.

One of the benefits of MOOCs is the ability to make frequent updates to reflect changes in technology or the thinking on a subject. Eric Lander, a biologist at MIT, teaches an introductory biology class that he has adapted into a MOOC for edX. He taught it for the first time in March, and will run it again in September. But before that, he plans to revise it, adding new video lectures to reflect lessons learned during the first course. "We asked ourselves, 'If we have access to Web-based media, how would we do the course differently for online students?"' says Lander. For his team, the answer was to inject technologies that they had not used before, namely animations and three-dimensional models.

Another prized advantage of MOOCs is the discussion boards. These need to be guided and monitored, but they can host intense debates and thought-provoking dialogues about the subject matter, the course and even the instructor. And active boards encourage students to rate peer comments, often creating a chatting frenzy. They also allow for peer-to-peer learning, with students, for example, coaching each other on homework assignments or helping to review each other's quiz results.

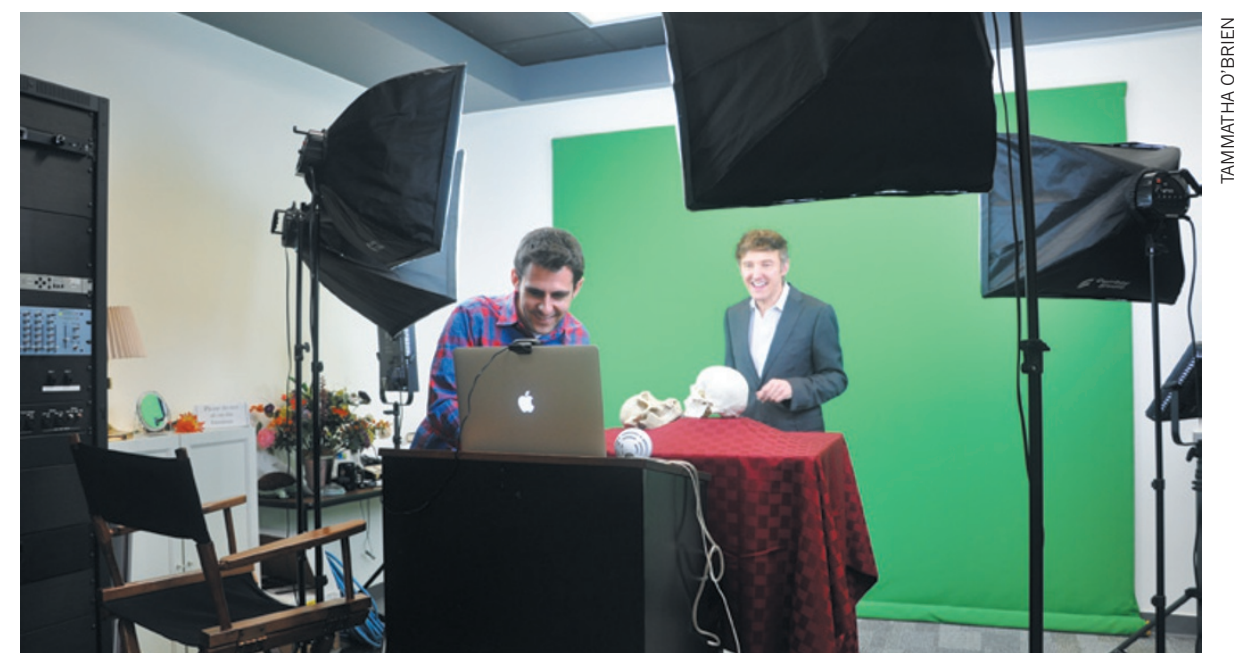

Graduate student Brian Lovett helps teacher Raymond St. Leger set up for a palaeogenomics lecture.

When it comes to designing a MOOC, instructors recommend that first-timers recruit a support team - perhaps including curriculum-development specialists, computer programmers, videographers or tech-savvy teaching assistants - to help them to clear pedagogical and technical hurdles (see 'Get started in MOOCs'). "It takes a village," says Lander. "I've taught my course for 23 years, and I know the material, but I needed help to convert it to a new platform, so it was good to have the outside expertise," he says. On campus, his course enrols as many as 850 students at a time; online, it drew some 35,000 students.

\section{STANDING OUT IN THE CROWD}

Most MOOC companies offer comprehensive services to help instructors to design their classes, assess student learning and create assignments. Some instructors think that these systems make the courses more generic by, for example, removing the distinct voice of the teacher. But many believe that the benefits outweigh the downside: sacrificing some personal lecturing style allows them to simplify the MOOC-creation process and gain the input of technology experts. Practised instructors say that teachers should think about what they want the students to learn and experience, rather than letting the platforms drive the content.

Instructors should also rethink their lecture styles, even down to their body language. Enthusiastic teaching with broad gestures and loud voices may add drama in a lecture hall, but it is a distraction on a small screen. Veteran instructors recommend that novices record lectures in front of students in a lecture hall or in smaller groups, and that they take time to acclimatize to the technology - which can include high-tech cameras and green screens for inserting different background. "I had to learn to be more still because the camera picks up movement," says Raymond St. Leger, an entomologist at the University of Maryland in College Park, who taught a MOOC on Coursera in April. He worried about giving a leaden performance after lots of rehearsing. "I had to get used to teaching to a blinking light on the camera and learn how to be more spontaneous."

"Overall, I think there's an optimal mix of entertainment and instruction that keeps students interested while still being useful for learning the material," says Michael DeWeese, a physicist at the University of California, Berkeley, who has taught an introductory physics class as an online course. It is now posted on YouTube.

\section{KNOW YOUR AUDIENCE}

It is crucial to consider who the students will be. Some may have degrees in the discipline, but others will have little or no experience. Veteran instructors say that it is essential to provide background information that lays out basic principles and knowledge early in the course.

"Online students are different from students on campus," says Michael Evans, a chemist at the University of Illinois at Urbana-Champaign, who has worked with his $\mathrm{PhD}$ supervisor, Jeffrey Moore, to design and teach an organicchemistry course on Coursera. "Online students are older and they're looking for real-world 
applications for what they're learning."

Evans says that instructors need to be imaginative with their lectures because they do not have forces such as peer pressure keeping students in seats, as they would in the classroom. "People have different ways of teaching things, but with video, you only have one chance to say something," says Evans, noting that a failure to keep the online class engaged can result in hundreds, if not thousands, of students logging off. "There are no tangents or wandering off. You get a snapshot in time, and it doesn't allow for even good digressions." He suggests avoiding anecdotes and verbal detours that make sense in the classroom but might not work online.

\section{COURSE UNCERTAINTIES}

Some sceptics remain doubtful that MOOCs can foster a satisfactory learning experience, no matter what technologies are used. They worry that students do not acquire the same breadth of knowledge as in a classroom-based course, and that potentially important bits of content can be left out. Efforts such as discussion boards do not really create a sense of community that replicates a classroom, says Carl Wieman, director of the Carl Wieman Science Education Initiative at the University of British Columbia in Van-

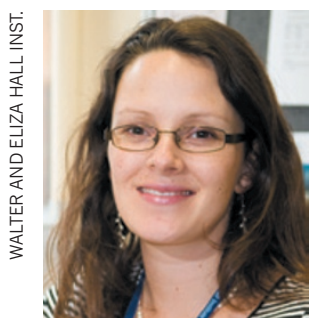
couver, Canada. "I wouldn't deny that's possible," he says. "I would deny that anybody has demonstrated they have technology that can do it."

Concerns such as these can be

"It is a very different feeling from a regular university course." Marnie Blewitt mitigated by community-building technologies that allow students to build connections with each other and their teachers. Instructors can offer one-on-one discussions using Web-based communications programmes; they can also get involved in interactions on discussion forums.

For early-career instructors, the broad appeal of MOOCs can offer something else: name recognition. "Younger faculty do see it as an opportunity for fame, if not fortune," says Evans. "You can really get your name out there far faster." That means that the stakes are high. "We taught more students in this one course," says St. Leger, "than we probably will teach in person for the rest of our careers." -

Sarah Kellogg is a freelance writer in Washington DC.

\section{TURNING POINT}

Thijn Brummelkamp

Thijn Brummelkamp will receive a Gold Medal and $€ 10,000$ (US\$13,000) in September from the European Molecular Biology Organization (EMBO), based in Heidelberg, Germany, for co-developing techniques that allow genes in human cells to be inactivated. A geneticist at the Netherlands Cancer Institute (NKI) in Amsterdam, Brummelkamp also co-founded Haplogen, a company in Vienna that aims to identify targets for drugs that treat infectious diseases. He details how he came to be known as an innovator and toolmaker.

How did you become interested in genetics? When I was young, I liked taking apart radios and televisions. DNA comes close to that: you can break it down and see the consequences. When I started my PhD at the NKI, my project was to identify genes that play a part in cancer. I became frustrated by the limited options for studying the genetics of human cells as opposed to those of model organisms. You cannot do genetic crosses in human cells.

\section{What did you do to tackle this problem?}

A colleague and I made a DNA construct to produced hairpin-shaped RNA molecules that silenced genes indefinitely. In the two or three months after we published the research in 2002, about 1,500 people asked for our reagents. You expect a few reactions, but not 1,500. More than 10 years later, people still use hairpin RNAs to examine gene function in human cells. You can make libraries of these hairpin RNA molecules, silence many genes and see which gene is linked to a phenotype of interest.

\section{What did you do after your PhD?}

I became a Whitehead Fellow at the Whitehead Institute for Biomedical Research in Cambridge, Massachusetts. The fellowship allows you to work for several years as a group leader without the stress of a tenure clock. And it gives you the freedom to find and start projects.

\section{In 2005, you were named one of the top} innovators under the age of 35 by MIT

\section{Technology Review. How did you feel?}

I'd heard of the list, but it was a surprise. It's wonderful to be recognized so early in your career. That can help to convince people to come to your lab, and that is important in the beginning.

What challenges did you face when you moved to the NKI in 2010?

Moving a lab definitely involves some logistics. It takes years to set yourself up - you need to train people, and write grants and

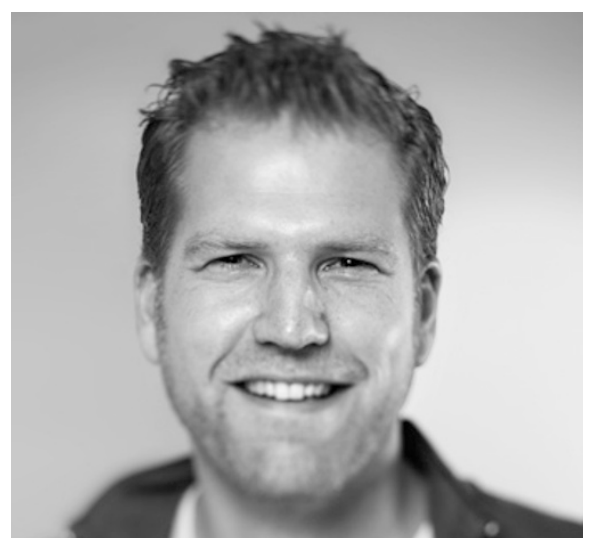

safety protocols. If you switch continents, suddenly it all needs to be done again. Not all my lab personnel joined me, so I lost people with experience. Also, transferring grants is not always easy. Almost all animal and safety protocols are different: for example, virus safety-level categorizations can differ from country to country. This slowed things down a bit. I had to wait before experiments could be done, and some experiments that could not have been performed here were done by collaborators in the United States. But now things are fine.

\section{How did co-founding Haplogen affect your career?}

It's one of the most exciting things I've ever been involved in. You meet entirely different people - people who work in companies and who help with financing. I'm learning more about the process of drug development, and that's an entirely different world.

\section{What was your reaction when you won the EMBO Gold Medal?}

I had not expected I would be considered, let alone that I'd receive it. It's wonderful because many people have noticed it, and I've already had some invitations to seminars and meetings because of it. It's a bit frightening because the expectations might be difficult to live up to.

Do you have any advice for graduate students and postdocs?

What has helped me is being involved in making tools. We could look at known biological problems with new techniques. If you make the tool yourself, you have first access and the most experience with it. That has kept us in business. 